\title{
Variatie en verankering bij progressiefconstructies in het Nederlands
}

\section{Maarten Lemmens*}

In zijn boek Construction Morphology presenteert Geert Booij een morfologisch model waarbinnen de notie "constructie" een centrale rol speelt. Een dergelijk constructioneel model laat toe, aldus Booij, om de relatie tussen syntaxis, morfologie en lexicon beter te beschrijven, waarbij de gelijkenissen tussen woord- en zinsformaties verklaard kunnen worden. Op die manier sluit Booijs morfologisch model aan bij het ruimere theoretische kader van de constructionele grammatica (Construction Grammar) die de laatste decennia sterk opgang heeft gemaakt (zie o.a. Goldberg 1995, 2006, Croft 2001, Tomasello 2003). In plaats van morfemen te zien als zelfstandige entiteiten zoals de "traditionele" morfologie dat doet, ziet het constructionele model morfemen als constructies die echter niet meer gezien worden als minimale linguïstische units ("independent linguistic signs", pag. 15). In de constructionele morfologie geldt immers het woord als minimale unit; een (gebonden) morfeem is een deel van een morfologisch schema en de betekenis van dit morfeem kan enkel worden benaderd via de betekenis van het morfologische schema waar het deel van uitmaakt.

In deze optiek verschillen morfologische schema's in wezen niet erg van syntactische schema's, vooral indien deze laatste "constructional idioms" (Jackendoff 2008) zijn. Dergelijke constructionele uitdrukkingen zijn betekenisvolle units waarvan een deel lexicaal gespecificeerd is, terwijl een ander deel variabel is. De progressiefconstructie aan het $<V$ $I N F><V-F I N>$ is, zo betoogt Booij, een dergelijke constructionele uitdrukking, waarbij een deel lexicaal gespecificeerd is (aan het) en andere delen variabel zijn, met name het werkwoord in de infinitief ( $V-I N F$, vb. aan het wachten/fietsen/denken/schoonmaken/etc.) maar ook het finiete werkwoord (vb. aan het V-INF zijn/brengen/zetten/slaan). De graad van variabiliteit voor de open posities is in deze constructie verschillend: de eerste $(V$-INF) is maximaal open en laat eender welk werkwoord toe dat semantisch compatibel is met de progressief, terwijl de lijst van mogelijke werkwoorden voor het tweede $(V-F I N)$ erg beperkt is (met zijn als meest frequente instantiatie, cf. infra).

Met de discussie van de aan het $V$-INF-progressiefconstructie verlaat Booij het traditionele domein van de morfologie, ook al blijft er een (semantische) link met gebonden morfemen die andere talen soms gebruiken om de progressief uit te drukken (zoals bijvoorbeeld het $-u$ -

\footnotetext{
* B.P. 60149, F-59653 Villeneuve d'Ascq Cedex, France; Université Lille 3 \& CNRS UMR STL 8163; email: maarten.lemmens@univ-lille3.fr
} 
morfeem in Odia, een Indo-Ariaanse taal, zie Lemmens \& Sahoo, subm.) waar het Nederlands een perifrase gebruikt. Booijs analyse van deze constructie als gegrammaticaliseerde constructionele uitdrukking is overtuigend: hij toont duidelijk aan dat de constructie welbepaalde formele eigenschappen vertoont die niet voorkomen bij andere prepositionele complementen met aan (vergelijk met bijvoorbeeld Jan zit aan de tafel of Jan is/gaat aan het werk). De aan het V-INF kan net als een "constructie" beschouwd worden omwille van die (a priori onvoorspelbare), idiosyncratische formele eigenschappen, in combinatie met een specifieke (eveneens onvoorspelbare) betekenis van het geheel m.a.w. een betekenis die niet kan worden afgeleid uit de combinatie der delen, in dit geval "progressief": "the progressive meaning of this $z i j n+\mathrm{PP}$ sequence cannot be derived compositionally from the meaning of its parts" (pag. 151).

De argumenten die Booij aanhaalt in zijn analyse staven zonder enige twijfel dat de aan het $V$-INF-constructie kan beschouwd worden als een "productive multi-word combination pattern that serves as an alternative to the morphological expression of lexical and/or grammatical content" (pag. 167), ontstaan door grammaticalisatie, aldus Booij. Dat laatste is zeker waar, maar wordt geponeerd op basis van een synchrone analyse en niet op basis van een diachrone analyse, een beperking die Booij overigens zelf ruiterlijk toegeeft; zijn focus ligt op de invloed van een dergelijke constructie op de synchrone grammatica.

Hoewel onze globale evaluatie positief is, zijn er een aantal meer kritische opmerkingen die we hier graag naar voren brengen. Ten eerste valt het op dat de titel van het hoofdstuk melding makt van progressiefconstructies (meervoud), terwijl de analyse in feite slechts betrekking heeft op één van de verschillende progressiefconstructies in het Nederlands, de aan het V-INF. Hoewel dit ogenschijnlijk een detail lijkt, leidt dit toch tot twee belangrijke theoretische opmerkingen: de eerste, onomasiologisch van aard, heeft betrekking op de verschillende progressiefconstructies in het Nederlands (en in andere Germaanse talen); de tweede betreft het statuut van de aan het $V$-INF-constructie zelf. Laat ik deze twee aspecten in wat volgt even verder toelichten.

Ten eerste, voortbouwend op Bertinetto et al (2000), maakt Booij in zijn inleiding duidelijk dat er twee belangrijke bronnen zijn voor progressiefconstructies in Europese talen: de locatief constructies (waaronder de aan het $V$-INF-constructie met oorspronkelijk locatief voorzetsel aan) en constructies met positiewerkwoorden. ${ }^{1}$ Dit is eigenlijk een beetje te kort

${ }^{1}$ Booij vermeldt (pag. 148) dat het Franse en train de ook van een locatief constructie is afgeleid, maar dat is niet zo; volgens de etymologische informatie in de TLFi (Trésor de la langue française informatisé) betekende train oorspronkelijk (ca. 1180) een manier van 
door de bocht, aangezien er nog andere constructies zijn die in het Nederlands, maar ook in de andere Germaanse talen, gebruikt worden om de progressief uit te drukken. De algemene opdeling is deze tussen enerzijds constructies die in oorsprong locatief waren en anderzijds (meer perifere) constructies, afgeleid uit andere uitdrukkingen. De groep van locatieve constructies kan opgedeeld worden in drie subgroepen: positiewerkwoorden (bijvoorbeeld $I k$ zit te lezen; Hij staat goed te tenissen; Het schip ligt in het dok te roesten), bewegingsuitdrukkingen (bijvoorbeeld Zij loopt de hele dag te zingen), of locatieve preposities (bijvoorbeeld Jan was de auto aan het wassen). ${ }^{2}$ De perifere constructies hebben een meer uiteenlopende oorsprong, maar kunnen grosso modo in twee groepen worden opgedeeld: (i) deze met BEZIG-uitdrukkingen, zoals bijvoorbeeld Ik ben bezig een brief te schrijven en (ii) deze met HOUD-werkwoorden; in het Engels heb je bijvoorbeeld keep on Ving; in het Zweeds wordt de progressief courant uitgedrukt met gegrammaticaliseerd hålla ('houden'), bijvoorbeeld Jag hållar på att skriva ett brev (lett. ik houd op/aan te schrijven een brief = 'Ik ben een brief aan het schrijven'); in het Noors doe je dat met holde. Schematisch kan je de verschillende mogelijkheden als volgt voorstellen (aangepast van Lemmens 2003):

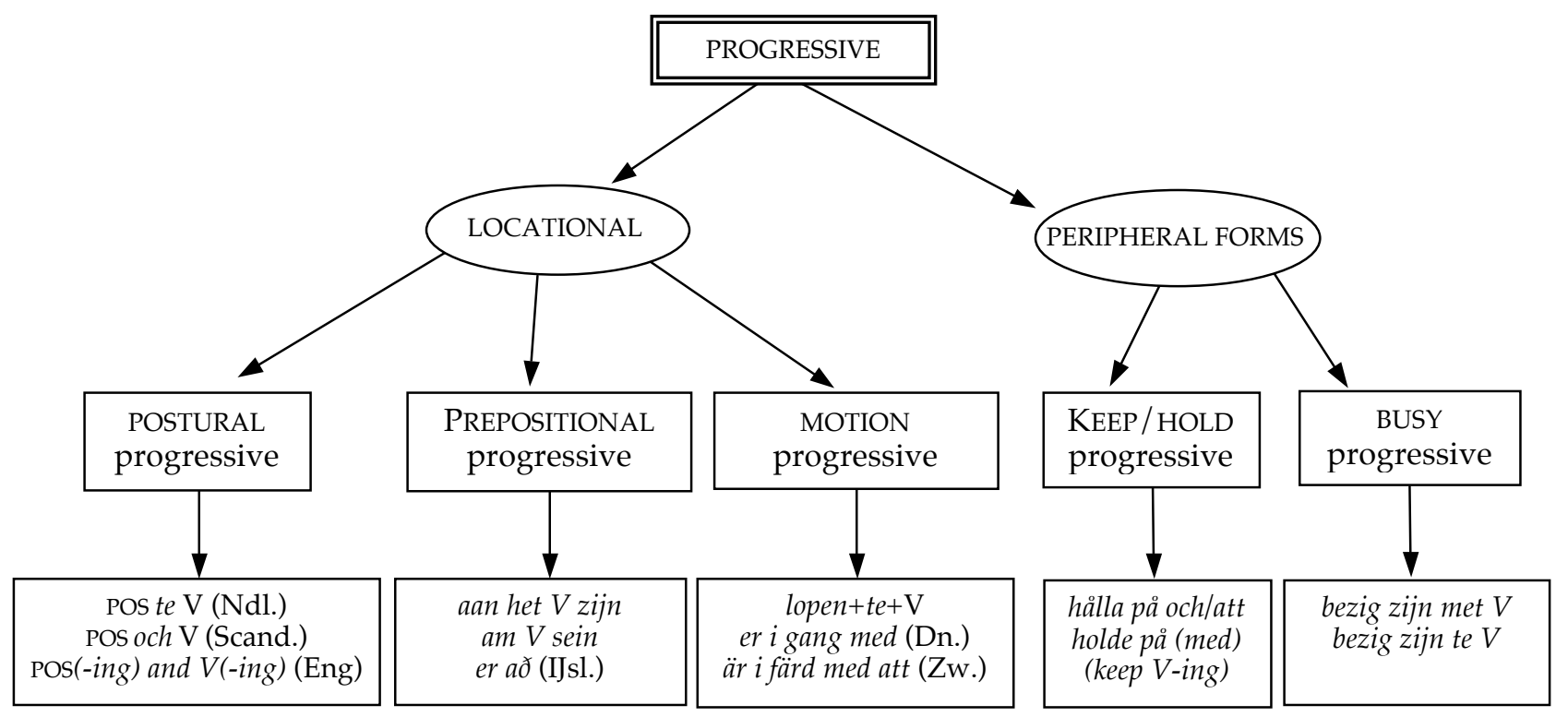

Figuur 1: Schematische voorstelling van (Germaanse) progressiefconstructies

Booijs focus is beperkt tot één van de mogelijkheden voor het Nederlands (aan het V-INF). Op zich is er duidelijk niets mis met een dergelijke beperking, maar het hoofdstuk lijkt sterk te suggereren dat deze constructie de default progressief zou zijn, en dat is slechts ten dele

handelen ("manière d'agir, de vivre d'une personne") van waaruit de progressief être en train de faire qqch. is ontstaan.

${ }^{2}$ We geven hier enkel voorbeelden uit het Nederlands, maar in de verschillende Germaanse talen vind je equivalenten hiervan, zoals aangegeven in Figuur 2. 
juist. Corpus-onderzoek (zie Lemmens 2003, in voorb.) toont immers dat de progressief met behulp van de positiewerkwoorden (liggen/zitten/staan + te $+V$-INF) globaal genomen frequenter is dan de aan het $V$-INF-constructie. Bovendien selecteren beide constructies bij voorkeur verschillende werkwoorden en/of verschillende contexten. In het INL-corpus materiaal gebruikt voor Lemmens (2003) - hetzelfde als dat gebruikt voor Lemmens (2005) zijn er meer voorkomens van de progressief met liggen/zitten/staan + te $+V$ (1373) dan deze voor met aan het Vzijn (1040). Voor de progressief met positiewerkwoorden is echter minder variatie in de werkwoorden dan voor aan het $V$ zijn constructie (354 vs. 447 verschillende werkwoorden). Slechts 9,8\% (74 werkwoorden op een totaal van 727) komt in beide constructies voor, hetgeen sterk aangeeft dat beide constructies verschillende werkwoorden selecteren.

Booijs formulering betreffende de constructies met positiewerkwoorden is overigens wat ongelukkig en suggereert m.i. te sterk dat dit in het Nederlands enkel kan met zitten: "Instantiations of the first type of construction in Dutch are combinations of the verb zitten "to sit' with an action verb" (p. 146), hetgeen uiteraard niet is wat Booij hier wenst te zeggen.

De tweede, en belangrijkere, bedenking bij het gebruik van de meervoudsvorm in de titel betreft de aan het $V$-INF-constructie zelf. Booij beargumenteert in dit hoofdstuk, zoals eerder al vermeld, dat deze constructie een gegrammaticaliseerde constructionele uitdrukking is (in de zin van Jackendoff 2008). Moeten we dan, zoals de meervoudsvorm aangeeft, de verschillende realisaties van deze constructie (d.w.z. met verschillende finiete werkwoorden, bijvoorbeeld aan het $V$ zijn/zetten/brengen) als verschillende constructies beschouwen of niet? Dit is zeker geen onbelangrijke vraag: betreft Booijs argument één enkele, meer schematische, constructionele uitdrukking of net verschillende realisaties van deze constructie? Op pag. 156 vermeldt Booij, eerder terloops, dat constructies als aan het INF gaan opgenomen kan worden in het lexicon ("listing constructional idioms such as aan het INF gaan in the lexicon"), maar dit wordt niet verder uitgewerkt.

Het is jammer dat Booij geen overzichtelijk "constructioneel schema" geeft voor al deze varianten (subschema's) om de discussie wat te verduidelijken. Een dergelijk schema zou er als volgt kunnen uitzien. De eerste accolade geeft de mogelijke keuze aan tussen de verschillende types werkwoorden in de infinitief; de tweede geeft de verschillende mogelijkheden aan voor het finiete werkwoord (zijn/brengen/zetten etc.) waarvan zijn zonder twijfel het meest frequent is. 


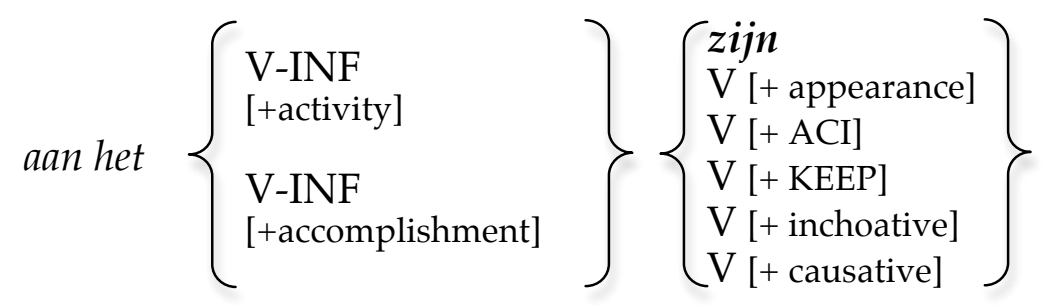

Figuur 2: Schematische voorstelling van de aan het $V$-INF-constructie

Op deze manier krijgt de lezer (zeker als deze het Nederlands niet eigen is) niet alleen een beter overzicht van de verschillende mogelijkheden, maar kan je ook zien hoe ze samen één (abstractere) constructie vormen.

In de constructionele grammatica, het model waarin Booij zijn werk situeert, worden deze varianten gezien als "instantiaties" in een netwerk van semantische en formeel gerelateerde constructies (waarvan het schema hierboven een samengeklapte versie is). In dit hoofdstuk, maar ook in de andere hoofdstukken van het boek, spreekt Booij eerder oppervlakkig over dergelijke constructie-netwerken.

In een echt doorgedreven usage-based constructionele benadering, zou overigens ook aandacht uitgaan naar de frequentie van de verschillende subconstructies binnen dit schema, die kunnen beschouwd worden als nog idiomatischer of zelfs als "prefabs", opgeslagen in het geheugen (cf. Bolinger 1975, Bybee 2006). Zo vermeldt Booij in zijn hoofdstuk nergens dat de combinatie met zijn het meest courant is en dat dus aan het $V$ zijn allicht het prototype van deze constructie is. Bovendien kan je binnen elk van de subschema's ook nog specifieke instantiaties zien die erg frequent zijn en dus, in cognitief-linguïstische termen, entrenched ('verankerd') zijn in de mentale grammatica. Hoewel dit gestaafd moet worden met doorgedreven corpusanalyse, lijkt het me bijvoorbeeld dat de combinatie met causatief zetten als finiet werkwoord vooral gebruikt wordt in de specifieke gebruikswijze iemand aan het denken zetten terwijl het causatieve brengen eerder werkwoorden als lachen, huilen, of twijfelen selecteert. Iemand aan het twijfelen zetten is allicht mogelijk, maar voelt intuïtief nogal onidiomatisch aan.

Kortom, Booij breekt dan wel een lans voor constructionele uitdrukkingen (constructional idioms), zijn analyse is m.i. te weinig gestoeld op daadwerkelijke gebruikswijzen (in tegenstelling tot recent corpus-gebaseerd werk binnen de constructiegrammatica) en mist daardoor de overtuigingskracht die ze verdient. Booij geeft duidelijk aan dat zijn analyse niet 
op corpusmateriaal is gebaseerd ${ }^{3}$, maar zijn analyse zou veel overtuigender zijn geweest indien hij aandacht had besteed aan dergelijke gecontextualiseerde gebruikswijzen waar vaak een semantisch-pragmatische motivering achter schuilt. In het algemeen besteedt Booij overigens weinig aandacht aan de semantische component van de aan het $V$-INF-constructie en dat is jammer.

Door geen (exhaustief) gebruik te maken van authentiek corpusmateriaal verliest Booij af en toe bepaalde dingen uit het oog. Zo stelt hij bijvoorbeeld (pag. 166) dat een tegenwoordig deelwoord (als synthetische uitdrukking van progressief aspect) ongrammaticaal is voor de

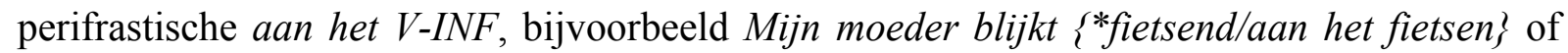
We gingen \{*fietsend/aan het fietsen\}. Wat Booij echter lijkt te ontgaan, is dat dit wel mogelijk is met houden, bijvoorbeeld Kun jij die motor \{draaiend/aan het draaien\} houden? (variatie op Booijs voorbeeld 33h). Met andere woorden, Booijs bewering dat "there are no synthetic forms available that express progressive aspect and can be used in predicative position" (p. 165) is niet helemaal juist.

Een corpusanalyse had ook meer diepgang kunnen brengen betreffende de prototypiciteit van bepaalde gebruikswijzen of hun regionale verschillen. In aanvulling op wat eerder reeds werd vermeld inzake prototypische combinaties, vermeld ik graag het volgende voorbeeld. Booij vermeldt op pag. 153 dat de aan het V-INF kan voorkomen bij o.m. accusativus-cuminfinitivo werkwoorden, bijvoorbeeld Wij hoorden hem op zolder aan het rommelen (vb. 15), of Ik zag haar aan het wieden in de tuin (vb. 16), maar de variant met de kale infinitief (Wij hoorden hem op zolder rommelen en Ik zag haar wieden in de tuin) lijkt toch frequenter, tenminste voor de schrijver dezes, moedertaalspreker van het Belgisch Nederlands. Hetgeen me naadloos bij het tweede punt brengt, de regionale verschillen. Sommige van Booijs observaties hebben betrekking op gebruikswijzen die, althans volgens mijn intuïtie, beperkt lijken te zijn tot Noord-Nederlands. Zo bijvoorbeeld Hij bleef de boeren aan het bedriegen (voorbeeld (36b), p. 156); in het Belgisch Nederlands lijkt me dit uitgesloten en heeft een kale infinitief (Hij bleef de boeren bedriegen) de voorkeur. ${ }^{4}$ Deze intuïties moeten uiteraard verder getoetst worden aan authentiek materiaal. Het valt te betreuren dat Booij weinig dergelijk

3 "The data presented here are taken partially from the Dutch reference grammar Algemene Nederlandse Spraakkunst [...] and partially constructed by myself as a native speaker of Dutch." (Booij 2010: 152)

${ }^{4}$ Vier moedertaalsprekers van het Belgische Nederlands aan wie ik Booijs voorbeeld (36b) heb voorgelegd, wijzen het resoluut van de hand als zijnde ongrammaticaal. Een informele zoekopdracht op Google lijkt inderdaad te bevestigen dat aan het $V$ blijven eerder voorkomt op .nl-pagina's dan op .be-pagina's, maar dit moet uiteraard verder onderzocht worden op basis van meer betrouwbare corpora. 
reliëf aanbrengt betreffende de frequentie en/of de regionale kleur van bepaalde gebruikswijzen waardoor zijn analyse aan overtuigingskracht verliest.

Wellicht kan corpusonderzoek ook meer duidelijkheid verschaffen over verschillen met aanverwante constructies. Zo zegt Booij (pag. 151) dat indien een zin als We zijn aan de wandel-ing al aanvaardbaar zou zijn, ze zeker niet als progressief geïnterpreteerd kan worden, in tegenstelling tot de (correcte) zin Wij zijn aan het wandelen. Deze observatie is helemaal juist, maar toch zijn er gevallen waar een ander substantief (process noun) mogelijk is in een aan het complement, bijvoorbeeld Wij zijn aan het werk (voorbeeld dat Booij zelf vermeldt op pag. 148) waar een progressief interpretatie niet helemaal uitgesloten lijkt. ${ }^{5}$ Ook al is dit niet de focus van het hoofdstuk, het zou interessant geweest zijn om, via corpus-analyse, te zien wat het verschil is tussen enerzijds aan het werk zijn en anderzijds aan het werken zijn. Merk op dat in sommige, meer idiomatische gebruikswijzen, een dergelijke alternatie niet mogelijk is, bijvoorbeeld aan de slag zijn/gaan heeft geen aan het V-INF equivalent.

In zijn gedetailleerde analyse merkt Booij terecht op dat de aan het $V$-INF-constructie een ondoordringbaar geheel vormt: bij transitieve werkwoorden wordt het object voor het geheel geplaatst (Ik ben een boek aan het lezen) en niet voor het werkwoord dat dit object projecteert (*ik ben aan het een boek lezen), terwijl dit laatste wel verwacht wordt voor het Nederlands als SOV-taal. Ook bijwoorden komen voor het geheel en niet voor het werkwoord (De jongens waren hard aan het fietsen/*aan het hard fietsen, vb. (39), pag. 159). Booij merkt op dat dit niet zo is voor gevallen van substantiefincorporatie waar het werkwoord gecombineerd wordt met een generisch substantief (aan het thee zetten), een niet gespecificeerd adjectief (aan het schoon maken), of een partikel (aan het afmaken). ${ }^{6}$ Verder wijst Booij er terecht op dat de substantieven in deze constructies een generische interpretatie dienen te hebben willen ze voor het werkwoord kunnen staan. Wanneer een bijkomende bepaling bij deze substantieven voorkomen, verliezen deze laatste hun generische interpretatie en kan de nominaalgroep niet langer direct voor het werkwoord komen: Ze zijn aan het brieven schrijven vs. Ze zijn \{lange brieven aan het schrijven / *aan het lange brieven schrijven\}. Booij vermeldt weliswaar dat "similar observations can be made for AV-combinations" (pag. 160), maar hij geeft enkel voorbeelden van generische adjectieven voor het werkwoord. Het lijkt me echter nuttig om ook voorbeelden toe te voegen met bijkomende bepaling die

\footnotetext{
${ }^{5}$ Merk op dat ook hier een combinatie met zetten mogelijk (en zelfs typisch) is: Ik zette hem aan het werk, hetgeen de parallel met de aan het $V$-INF constructie versterkt.

${ }^{6}$ We volgen hier Booijs (terechte) keuze om deze woorden van elkaar te schrijven ondanks de conventionele spelling als één woord.
} 
hetzelfde effect illustreren als deze met substantieven. Neem bijvoorbeeld onnozel doen, dat beide constructies toelaat: Zij waren onnozel aan het doen of Zij waren aan het onnozel doen. Wanneer je echter een bijkomende bepaling aan het adjectief toevoegt, is enkel de eerste constructie toegestaan: Ze waren erg onnozel aan het doen / *Ze waren aan het erg onnozel doen. Booij verwijst naar de bespreking van dergelijke "incorporations" in Hoofdstuk 4 van het boek; deze hebben echter ook enkel betrekking of $\mathrm{N}+\mathrm{V}$ combinaties, vb. piano spelen, mast klimmen, e.d. en Booij laat combinaties met een adjectief buiten beschouwing. Voor de combinaties met partikels wordt dat dan weer wel geillustreerd (p. 162): helemaal af aan het maken vs. *aan het helemaal afmaken (vs. aan het af maken).

Laat ik even samenvatten. Dit hoofdstuk presenteert m.i. op overtuigende wijze dat de aan het $V$-INF-constructie een gegrammaticaliseerde constructie is in het Nederlands, met een specifieke (niet-voorspelbare) semantische waarde (“progressief”) en specifieke formele eigenschappen. Deze laatste wijzen vooral op de unificatie van de constructie tot één geheel, hetgeen vaker voorkomt bij gegrammaticaliseerde constructies. Booijs degelijke en gedetailleerde analyse van de aan het $V$-INF-constructie, vooral dan wat de vormelijke (morfosyntactische) kenmerken betreft, geeft een sterk argument voor het bestaan van constructionele uitdrukkingen (constructional idioms), deels gelexicaliseerd, deels variabel die, volgens de constructiegrammatica, deel uitmaken van een complex, hiërarchisch gestructureerd netwerk van constructies. Op die manier levert Booij een erg waardevolle bijdrage aan het model van constructionele grammatica, in het bijzonder omdat zijn werk het domein van de morfologie betreft, nogal eens het kleinere broertje in het model. Het hoofdstuk over de aan het $V$-INF-constructie is niet zuiver morfologisch (in de traditionele definitie), maar slaagt er net in een brug te slaan tussen morfologie en syntaxis.

Ergens is het wel jammer dat Booij de constructionele benadering slechts ten dele volgt en niet echt vertrekt van een usage-based model, d.w.z. een model dat kijkt naar hoe dergelijke constructies vanuit contextuele gebruikswijzen ontstaan en verankerd geraken. Een dergelijke benadering zou veel meer dan nu het geval is semantische aanvullingen kunnen geven alsook meer duidelijkheid over de verschillende, meer specifieke instanties van de aan het V-INFconstructie, waarbij hun token- en typefrequentie mee in rekening worden gebracht. De eerste draagt bij tot de verankering (entrenchment) van een (specifieke) structuur in het taalsysteem, de tweede tot abstrahering (schematisation) resulterend in meer algemene (d.w.z. variable) structuren (cf. Tomasello 2000). Het lijkt mij daarbij noodzakelijk om ook te kijken naar regionale verschillen die belangrijker zijn dan Booij lijkt te veronderstellen. 
Op zich doet de afwezigheid van een echte, usage-based benadering geen afbreuk aan de kwaliteit van Booijs analyse; het maakt wel dat de algemene bewijsvoering ter staving van het bestaan van constructionele uitdrukkingen minder sterk is dan ze had kunnen zijn. Het leidt echter geen twijfel dat Booij met dit hoofdstuk (en met het hele boek eigenlijk) een stevige basis heeft gelegd voor een constructionele morfologie die verder uitgebouwd kan worden tot een volwaardig usage-based model.

\section{Bibliografie}

Bolinger, D. (1976). Meaning memory, Forum Linguisticum 1, 1-14.

Croft, W. (2001). Radical Construction Grammar. Syntactic Theory in Typological Perspective. Oxford: Oxford University Press.

Bybee, J. (2006). From usage to grammar: the mind's response to repetition. Language, 82, 711-733.

Jackendoff, R. (2008). Construction after construction and its theoretical challenge. Language 84, 8-28.

Lemmens, M. (2003). Germanic Progressives Revisited, Ninth Germanic Linguistics Association Conference, Buffalo New York, 25-27 april.

Lemmens, M. (2005). Aspectual posture verb constructions in Dutch, Journal of Germanic Linguistics 17, 183-217.

Lemmens, M. (in voorb.). A collostructional analysis of two Dutch progressive constructions.

Lemmens, M. \& K. Sahoo. (subm.). Something gotta go, something gotta give. Odia light verb constructions. Journal of Linguistic Typology

Goldberg, A.E. (1995). Constructions. A Construction Grammar Approach to Argument Structure. Chicago : Chicago University Press.

Goldberg, A.E. (2006). Constructions at work: The Nature of Generalisation in Language. Oxford: Oxford University Press.

Tomasello, M. (2000). First steps toward a usage-based theory of language acquisition, Cognitive Linguistics 11, 61-82.

Tomasello, M. (2003). Constructing a language. A usage-based theory of language acquisition. Cambridge, Ma. : Harvard University Press. 